\title{
(DES)PROTECCIÓN DE PERSONAS LGTBI EN ESPACIOS SEGUROS. UN ANÁLISIS DE LAS EXPERIENCIAS MIGRATORIAS EN GUATEMALA Y MÉXICO
}

\section{LGBTI (DE)PROTECTION IN SAFE SPACES. AN ANALYSIS OF MIGRANTS EXPERIENCES IN GUATEMALA AND MEXICO}

Eloísa González Hidalgo* y Daniela Lo Coco**

Resumen: La vulnerabilidad de las personas lesbianas, gais, transexuales, bisexuales e intersexuales (LGTBI) durante su proceso migratorio ha generado una nueva preocupación en la comunidad internacional. En las últimas décadas se ha tenido en cuenta esta diversidad para generar mecanismos de protección, uno de ellos es la Red de Espacios Seguros (RSSN) en Centroamérica y México, bajo el ACNUR. Sin embargo, el camino para disminuir el grado de vulnerabilidad es complejo.

* Ex becaria postdoctoral del Instituto de Derechos Humanos Pedro Arrupe, Universidad de Deusto, España (eloisagh@deusto.es).

** Este artículo está basado en el trabajo empírico de una investigación encargada al Instituto de Derechos Humanos Pedro Arrupe de la Universidad de Deusto financiado por la Agencia Española de Cooperación Internacional para el Desarrollo y apoyado por el ACNUR y algunas de sus oficinas en América Latina (ID No. CONMEN/2018/0000000026). Como resultado de dicha investigación se produjo el informe de recomendaciones: Morondo Taramundi, Dolores y Lo Coco, Daniela, "El estudio sobre la situación de las personas LGTBI del norte de centro-américa con necesidades de protección internacional en Guatemala y México", AECID 2018. Daniela Lo Coco es estudiante pre-doctoral FPI en el Instituto Pedro Arrupe de Derechos Humanos de la Universidad de Deusto (maiteblancolococo@deusto.es). 
$\boldsymbol{E} \boldsymbol{l}$ objetivo de este artículo es evidenciar las lagunas en la protección de las personas LGTBI en los espacios seguros en México y Guatemala. La metodología se apoya en la revisión de fuentes secundarias y en el trabajo de campo en el que se llevaron a cabo observaciones directas, grupos de discusión y entrevistas en profundidad a personas en tránsito, solicitantes de asilo y refugiadas LGTBI.

Palabras clave: ACNUR; derechos humanos; espacios de protección; migración; LGTBI.

Abstract: In recent times, the vulnerability of LGBTI people among migrants have raised a strong international concern. Especially during the last decades, international actors have included sexual orientation and gender identity (SOGI) in their policies of protection. In this regard, UNHCR has created the Regional Safe Spaces Network (RSSN) in the Americas in which LGBTI modules are included addressing specific needs and vulnerabilities. Despite $R S S N, L G B T I$ vulnerability remains significantly high in the region.

The goal of this article is to show the protection gaps of $L G$ BTI people in shelters members of the RSSN in Guatemala and Mexico. Methodologically the research is divided in two parts firstly, the analysis of secondary data and secondly two months fieldwork where in deep interviews, focus groups and direct observation at the borders have been conducted with migrants in transit, asylum seekers and refugees LGBTI in different shelters among the RSSN in Guatemala and México.

Key words: UNHCR; human rights; safe spaces; protection; migration; LGBTI.

A todas las personas que nos contaron su historia

\section{INTRODUCCIÓN}

Si bien es cierto que, actualmente, la diversidad de las sociedades es aceptada, también es fuente de discriminación y rechazo, especialmente en un entorno de movilidad humana. La vulnerabilidad de las personas lesbianas, gais, transexuales, bisexuales e intersexuales (LGTBI) durante su proceso migratorio, generó preocupación en la comunidad internacional en tanto grupo vulnerable. A partir de 2017, la Oficina del Alto Comisionado de las Naciones Unidas para 
los Refugiados (ACNUR) inició la construcción de la Red Regional de Espacios Seguros (RSSN) cuyo principal objetivo es proteger a grupos vulnerables a lo largo de las rutas migratorias de Centroamérica hacia Estados Unidos, entre ellos al LGTBI.

A efectos de este artículo se entenderá por LGTBI a las personas autodefinidas como Lesbianas, Gays, Transexuales, Bisexuales e Intersexuales. De acuerdo con Morondo y Lo Coco (2018), se trata de una etiqueta limitada debido a que engloba situaciones muy heterogéneas en torno a una característica que no poseen, cis-género heterosexual ${ }^{1}$.

El objetivo de este artículo es evidenciar la existencia de acciones y actitudes que desprotegen a las personas LGTBI en los albergues, ubicados a lo largo de la ruta migratoria en México y Guatemala, pertenecientes o en proceso de pertenecer a la RSSN.

Cabe mencionar que, en el momento de la investigación, los albergues visitados e incluidos en la investigación se encontraban en etapa de evaluación y negociación con el ACNUR para su inclusión en la RSSN. En este sentido, las visitas a éstos se realizaron bajo criterios del propio ACNUR, así como por la relevancia geográfica en las rutas más utilizadas por las personas migrantes.

Así mismo, es importante señalar la inexistencia de un documento oficial y público donde se establezcan los requisitos mínimos a cumplir de los albergues para ser parte de la RSSN.

\section{METODOLOGÍA}

La metodología utilizada en este artículo fue, en un primer momento, la recopilación y el análisis de fuentes secundarias. Primero, se estudió información relativa a la situación de la migración mundial, focalizándose en América Latina, posteriormente, se revisaron instrumentos internacionales relacionados con la protección a las personas pertenecientes al colectivo LGTBI, especialmente, en contextos de migración forzada; así como, informes y documentos emitidos por el ACNUR con respecto a la RSSN y literatura concerniente al significado de espacios seguros.

1 Véase: https://www.acnur.org/fileadmin/Documentos/Publicaciones/2014/ 9872.pdf 
En un segundo momento, se analizaron las fuentes primarias, integradas por catorce testimonios individuales de personas LGTBI, un grupo de discusión conformado por cinco personas LGTBI y siete testimonios de responsables de los albergues. Es decir, un total de veintiséis personas participantes en la investigación. Estos testimonios se recogieron, como información de contraste, durante el trabajo de campo realizado en los meses de febrero y marzo de 2018, en México y en Guatemala, en el que se visitaron 8 albergues. Asimismo, se realizaron dos observaciones, una de ellas en un punto de trabajo sexual frecuentado por mujeres transgénero en Quetzaltenango (Guatemala) y la segunda en la frontera entre Tecún-Umán (Guatemala) y Ciudad Hidalgo (México), llamado "el paso".

Con respecto a la identidad de género de los catorce testimonios individuales ${ }^{2}$ cinco corresponden a hombres homosexuales, ocho mujeres transgénero y una mujer lesbiana, mientras que el grupo de discusión estuvo integrado por cinco mujeres transgénero. En cuanto al estatus migratorio de estas diecinueve personas, dos eran personas desplazadas internas en Guatemala, seis refugiadas, ocho solicitantes de asilo, dos con visas humanitarias en México y una con protección complementaria. De las cuales corresponden a nacionales de Guatemala (3), Honduras (9) y El Salvador (7) (Ver Anexo 1).

Cabe destacar que, de las diecinueve personas migrantes, catorce recurrieron a albergues a lo largo de su ruta, excepto cinco (tres hombres homosexuales) por cuestiones de seguridad y dos personas desplazadas internas en Guatemala (una mujer lesbiana y una mujer transgénero). Pese a ello, las personas que no utilizaron los albergues fueron atendidas por servicios prestados por la RSSN.

Este artículo se divide en dos partes. En la primera se describe la situación del colectivo LGTBI en el contexto migratorio centroamericano y el papel del ACNUR a través de la RSSN. En la segunda parte, a través de testimonio de personas LGTBI migrantes, se evidencian las lagunas de protección existentes en la RSSN a lo largo de su ruta migratoria. Por último, se exponen las conclusiones.

2 Una entrevista a una pareja de hombres refugiados homosexuales se realizó en dos etapas diferentes del trayecto migratorio, en primer lugar, en Tapachula y más tarde en Saltillo (México). 


\section{MARCO CONCEPTUAL}

Tras la Segunda Guerra Mundial, los derechos humanos se han generalizado y positivizado a nivel internacional, regional y nacional hasta hacerse hegemónicos (Bobbio, 1990). A partir de la década de los 60, tanto a nivel social como jurídico, se empieza a concientizar de la existencia de grupos cuyas características concretas los hacen vulnerables y, por tanto, requieren protección específica, a saber, mujeres que si bien son una mayoría necesitan de ella; grupos indígenas, minorías nacionales, niñas y niños y personas discapacitadas. No ha sido sino hasta mediados de los años 2000 que las personas cuya orientación sexual e identidad de género difiere de la mayoría de la población, llamaron la atención y generaron preocupación en la comunidad internacional.

Actualmente, se entiende la diversidad de las sociedades, especialmente en un entorno mundial de movilidad humana; sin embargo, también la diversidad es fuente de discriminación, rechazo y desigualdad en oportunidades, lo cual genera la necesidad de continuar estableciendo y reforzando mecanismos de protección sobre la base de derechos específicos o diferenciados (Kymlicka, 1995; Parekkh, 2005; Prieto Sanchis, 1996).

En este sentido, se han desarrollado mecanismos universales y regionales de protección para dar respuesta a la situación de vulnerabilidad y violencia ejercida contra las personas LGTBI durante su proceso migratorio. El ACNUR es una de las instituciones responsables de implementarlos en respuesta a su mandato que es garantizar la protección internacional de las personas obligadas a migrar de manera forzada ${ }^{3}$, durante todo el proceso de migración.

Así mismo, se han creado otros instrumentos internacionales que, si bien no son vinculantes jurídicamente, sí reflejan principios establecidos en el derecho internacional que coadyuvan en la protección de las personas migrantes, algunos de ellos con especial atención en el colectivo LGTBI, por ejemplo, los Principios de Yogyakarta sobre la Aplicación de la Legislación Internacional de Derechos Humanos con relación a la Orientación Sexual y la Identidad de Género (Principio 23) ${ }^{4}$. A lo anterior se agrega el Pacto Mundial

\footnotetext{
3 Véase: https://www.acnur.org/es-mx/asilo-y-migracion.html

4 Principios de Yogyakarta - Principios sobre la Aplicación de la Legislación Internacional de los Derechos Humanos en Relación con la Orientación
} 
para la Migración Segura, Ordenada y Regulada resultado de la conferencia convocada por Naciones Unidas sobre migración, llevada a cabo los días 10 y 11 de diciembre de 2018.

En el cuadro siguiente se aprecia la evolución del desarrollo de los mecanismos para proteger a las personas LGTBI, tanto en el ámbito universal como en el regional, este último en el continente americano.

\section{CuAdro 1}

\section{PROTECCIÓN INTERNACIONAL A LA COMUNIDAD LGTBI}

\begin{tabular}{|c|c|}
\hline Universal & Regional \\
\hline $\begin{array}{l}\text { Principios de Yogyakarta sobre la Aplicación de la } \\
\text { Legislación Internacional de Derechos Humanos } \\
\text { con relación a la Orientación Sexual y la Identidad } \\
\text { de Género de 2006, principio } 23 \text {. }\end{array}$ & $\begin{array}{l}\text { Declaración de Cartagena de 1984, en la que se } \\
\text { desarrolla una definición de refugiado más amplia } \\
\text { que la establecida en el Convención de } 1951 \text {. }\end{array}$ \\
\hline $\begin{array}{l}\text { Resolución } 17 / 19 \text { del Consejo de Derechos Huma- } \\
\text { nos de las Naciones Unidas de julio } 2011 \text { que ex- } \\
\text { presa su "preocupación por los actos de violencia } \\
\text { y discriminación, en todas las regiones del mundo, } \\
\text { que se cometen contra personas por su orienta- } \\
\text { ción sexual e identidad de género". }\end{array}$ & $\begin{array}{l}\text { Relatoría sobre derechos de las personas LGTBI } \\
\text { de } 2011 \text {, cuya finalidad es reforzar la protección, } \\
\text { promoción y monitoreo de los derechos humanos } \\
\text { de las personas LGTBI }{ }^{5} \text {. }\end{array}$ \\
\hline $\begin{array}{l}\text { Directrices sobre Protección Internacional No. } 9 \\
\text { adoptadas por el ACNUR en octubre de 2012, para } \\
\text { brindar orientación interpretativa legal para los } \\
\text { gobiernos sobre la aplicación de del artículo 1A (2) } \\
\text { de la Convención sobre el Estatuto de los Refugia- } \\
\text { dos de } 1951 \text { y/o su Protocolo de } 1967 .\end{array}$ & $\begin{array}{l}\text { Resolución } 2721 \text { aprobada por la Asamblea Gene- } \\
\text { ral de la OEA en junio de 2012, que resuelve con- } \\
\text { denar la discriminación contra las personas debi- } \\
\text { do a su orientación sexual e identidad de género. }\end{array}$ \\
\hline $\begin{array}{l}\text { Resolución } 32 / 2 \text { del Consejo de Derechos Huma- } \\
\text { nos, de } 30 \text { de junio de } 2016 \text {, creó el mandato del } \\
\text { Experto Independiente sobre la protección contra } \\
\text { la violencia y la discriminación por motivos de } \\
\text { orientación sexual o identidad de género }{ }^{6} \text {. }\end{array}$ & $\begin{array}{l}\text { Declaración y Plan de Acción de Brasil "Un Marco } \\
\text { de Cooperación y Solidaridad Regional para Forta- } \\
\text { lecer la Protección Internacional de las Personas } \\
\text { Refugiadas, Desplazadas y Apátridas en } \\
\text { América Latina y el Caribe" de } 2014 \text {, en la que se } \\
\text { estableció un conjunto de prioridades operativas } \\
\text { para la protección de personas refugiados y gru- } \\
\text { pos vulnerables, entre ellos, el LGTBI7. }\end{array}$ \\
\hline
\end{tabular}

Sexual y la Identidad de Género, marzo de 2007, disponible en: http://yogyakartaprinciples.org/principles-sp/about/

5 Véase: http://www.oas.org/es/cidh/lgtbi/mandato/responsabilidad.asp

6 Véase: https://ap.ohchr.org/documents/dpage_s.aspx?si=A/HRC/RES/32/2

7 Véase: http://www.acnur.org/fileadmin/scripts/doc.php?file=fileadmin/Documentos/BDL/2014/9867 


\begin{tabular}{|l|l|}
\hline \multicolumn{1}{|c|}{ Universal } & \multicolumn{1}{c|}{ Regional } \\
\hline $\begin{array}{l}\text { Declaración de Nueva York sobre los Refugiados y y } \\
\text { los Migrantes adoptada por la Asamblea General } \\
\text { de Naciones Unidas en septiembre de 2016, en } \\
\text { la que se tomó una serie de compromisos para } \\
\text { mejorar la protección de las personas refugiadas } \\
\text { y migrantes }\end{array}$ & $\begin{array}{l}\text { Declaración de Acción de San José de 2016, en } \\
\text { la que se establecen acciones conjuntas en la re- } \\
\text { gión para garantizar la protección de los derechos } \\
\text { fundamentales de las personas solicitantes de la } \\
\text { condición de refugiado provenientes del Triángulo } \\
\text { Norte de Centroamérica, entre ellas, a las de la } \\
\text { comunidad LGTBI }\end{array}$ \\
\hline $\begin{array}{l}\text { Directrices sobre protección internacional No. 12 } \\
\text { de diciembre de 2016: Solicitudes de la condición } \\
\text { de refugiado relacionadas con situaciones de con- } \\
\text { flicto armado y violencia bajo el artículo 1A (2) de } \\
\text { la Convención de 1951 y/0 el Protocolo de 1967. }\end{array}$ & $\begin{array}{l}\text { Declaración de San Pedro Sula de 2017, que dio se- } \\
\text { guimiento a la Declaración de Nueva York y cuyo fin } \\
\text { es fortalecer la respuesta regional al desplazamien- } \\
\text { to mediante la implementación del Marco Integral } \\
\text { Regional para la Protección y Soluciones (MIRPS) }\end{array}$ \\
\hline
\end{tabular}

Fuente: elaboración propia con información del ACNUR y ONU.

Con respecto a la protección en los procesos migratorios, en 2010, el ACNUR llevó a cabo una mesa redonda de personas expertas sobre el tema ${ }^{11}$, concluyendo en la necesidad de elaborar nuevos mecanismos de protección en las diferentes etapas del proceso migratorio. Por ejemplo, el punto 20 menciona la obligación de realizar esfuerzos adicionales para asegurar que las personas LGTBI reciban servicios sin discriminación y adecuada por parte de los Estados, del ACNUR y de las ONG ${ }^{12}$.

Desde 2011, el ACNUR implementó la Política de Edad, Género y Diversidad que pone de relieve la importancia de las acciones dirigidas y la transversalización en temas relacionados con la población bajo su protección, incluida la LGTBI. Lo anterior se traduce en asistencia técnica a los gobiernos y su mismo personal en el terreno para el desarrollo de sus tareas en ese ámbito.

Además, el ACNUR en su informe sobre "Protección de las personas con orientación sexual e identidad de género diversas", publicado de 2015, señaló dos medidas de protección aplicadas en sus oficinas a nivel global. Por un lado, las medidas de recepción y registro sensibles de la población LGTBI y, por otro, la creación de 'espacios seguros' que se refiere a áreas seguras de espera, días u horas es-

8 Véase: https://refugeesmigrants.un.org/es/declaration

9 Véase: https://www.acnur.org/5b5109d54.pdf

10 Véase: https://www.acnur.org/5b58d6904.pdf

11 Mesa de expertos organizada por el Alto Comisionado de las Naciones Unidas para los Refugiados, Ginebra, Suiza, 30 de septiembre - 1 de octubre 2010.

12 Véase: https://www.refworld.org.es/type,LEGALPOLICY,4d11bb2a2,0.html 
peciales para que los solicitantes de asilo LGTBI se registren y una línea de apoyo para llamadas sobre el asilo con operadores capacitados en asuntos sobre Orientación Sexual e Identidad de Género (SOGI por sus siglas en inglés).

\subsection{El concepto de "espacios seguros"}

Dentro del ámbito de los derechos humanos el término "espacio seguro" es de reciente inclusión, la literatura sobre este tema es escasa, además de que es inexiste una definición concreta universalmente aceptada. Para algunas personas expertas, este concepto se refiere a un espacio físico, para otras es un espacio abstracto o, en ocasiones, aluden a ambos.

El término "espacio seguro" comenzó a emplearse a finales de los ochenta en el ámbito del derecho internacional humanitario, relacionado con el acompañamiento internacional y el mantenimiento civil de paz desarmado (Eguren, 2014). En algunos países de Centro América como fue el caso de El Salvador y Guatemala, tras la finalización de los conflictos de liberación nacional y su proceso de transición de las dictaduras hacia regímenes democráticos, se contó con la presencia de organizaciones internacionales no gubernamentales que generaron entornos seguros para que personas defensoras de derechos humanos, líderes sindicales o líderes comunitarios pudieran realizar su trabajo sin sufrir atentados o amenazas contra su integridad física mediante el acompañamiento internacional.

Otro ejemplo son las "comunidades de paz" o "comunidades en resistencia" surgidas finales de la década de los noventa, en Colombia, que son áreas de protección internacional para comunidades que fueron desplazadas por ofensivas militares y paramilitares y decidieron volver a sus tierras con estrategias políticas y comunitarias de protección tanto con el apoyo del acompañamiento internacional como de las organizaciones no gubernamentales locales, principalmente, eclesiásticas (Eguren y Mahony, 2004). Si bien, estos espacios son físicos, también son espacios abstractos, dado que para lograr un cierto grado de protección las organizaciones realizan una serie de actividades abstractas, por ejemplo, la concientización en temas relacionados con derechos humanos, paz y conflictos armados con la población en general y con las autoridades locales y nacionales; incidencia política y relaciones públicas (lobbying) tanto con el Es- 
tado colombiano como con la comunidad internacional para el conocimiento de la situación de vulnerabilidad y violación de derechos de las comunidades de paz (Eguren, 2014, p. 2).

Es decir, los espacios seguros son áreas físicas, pero con una extensión abstracta donde se establecen relaciones entre los diferentes actores inmiscuidos en un contexto determinado, quienes trabajan para alcanzar un bien común, por ejemplo, la protección de un grupo o colectividad determinada en un contexto de conflicto armado o de violaciones graves y masivas a derechos humanos.

Por su parte, Seelinder y Freccero (2013) se han centrado en el análisis de espacios físicos destinados a personas desplazadas por violencia sexual y de género con especial atención en la comunidad LGTBI, a saber, casas de acogida o refugios. Pese a la existencia de estos espacios seguros, la protección para las personas de la comunidad LGTBI fue extremadamente limitada por varias razones, entre ellas, la falta de concientización y capacitación sobre temas sobre perspectiva de género o derechos humanos por parte del personal encargado de los centros de acogida, así como por la estigmatización y el rechazo hacia ese colectivo desde de las sociedades donde se encontraban los refugios o casas de acogida. Es decir, faltó el espacio abstracto.

Lo anterior, permite tener una idea general del significado de espacio seguro, es decir, un espacio físico con una extensión abstracta donde deben interactúan a través de acciones comunes todos los actores inmiscuidos en una problemática relacionada con la protección de derechos humanos.

\subsection{ACNUR. Red Regional de Espacios Seguros}

Desde 2017, el ACNUR ha venido construyendo la RSSN, priorizando la región Norte de Centroamérica (NCA), Venezuela y varios países vecinos cuya población se ha visto en la necesidad de salir de su país de origen por cuestiones de violencia estructural, entre ella la sexual y de género.

Es bajo la RSSN que el ACNUR desarrolla lo que entiende como espacio seguro: espacio físico o móvil donde grupos o personas pueden sentirse "seguras", construir redes sociales, expresarse y entretenerse mientras reciben información y acceden a servicios de protección y asistencia de acuerdo con el enfoque de edad, género y diversi- 
dad, el enfoque centrado en la persona sobreviviente y el principio del interés superior de la niña o niño. (Dichos servicios móviles podrían ofrecer atención a mujeres y niñas, o a hombres y niños en el lugar donde éstos se encuentren, en lugar de obligarlos a viajar a un lugar fijo. Las clínicas de salud móviles, la difusión y asesoría grupal en áreas remotas son buenos ejemplos de tales servicios (ACNUR, 2018, p. 8). Es decir, espacios físicos y movibles accesibles a la población vulnerable.

La RSSN se asienta sobre una infraestructura de espacios, entre los que se encuentran albergues ya existentes en los ámbitos locales que forman parte de otros proyectos creados por diversas instituciones gubernamentales y no gubernamentales, sean estas nacionales o internacionales, sobre todo, de carácter eclesiástico. Para su implementación, el ACNUR impulsó esfuerzos de colaboración y coordinación. Este trabajo se lleva a cabo a través de financiación a diversos albergues, mapeo de servicios, apoyo técnico, creación de redes, intercambio de información y un trabajo de negociación capaz de convencer a los agentes que gestionan estos albergues o espacios para seguir las directrices, la inclusión de categorías de protección especial y las maneras de intervención del ACNUR.

La RSSN se coordina entre sí para proporcionar derivaciones a servicios especializados o llevar a cabo actividades de sensibilización en la comunidad de manera coordinada con las personas solicitantes de asilo, refugiadas, desplazadas internas, repatriados, personas en movimiento, apátridas y otras personas necesitadas de protección internacional.

En 2017, la RSSN comenzó con el apoyo de 50 miembros, incluidas agencias de las Naciones Unidas, agencias internacionales, organizaciones de la sociedad civil, organizaciones religiosas, instituciones nacionales y redes de personas voluntarias en las comunidades en México, Guatemala, Costa Rica, Venezuela, Colombia, Perú y Chile. A junio de 2019, el número de miembros se había incrementado a 110 incluyendo países de la región (ACNUR, 2019).

Tanto México como Guatemala se establecieron más sitios seguros dado que son países de origen y tránsito de migrantes. En el caso de México se incluyeron a socios locales que se encuentran en las principales rutas migratorias (Chiapas, Tabasco y Ciudad de México). En Guatemala se incluyeron socios de las regiones de Ciudad de Guatemala, Petén, Santa Elena e Izabal. 


\subsection{Análisis: experiencias (in)seguras en espacios seguros en Guatemala y México}

En este apartado se analizarán las experiencias de las personas LGTBI en los ocho albergues visitados. Se focalizará exclusivamente en los albergues debido a que son parte articuladora de la RSSN y son un pilar básico en ésta. Es importante recordar que, aparentemente, no existe un documento oficial donde se establezcan los criterios que deben cumplir los albergues para ser incorporados a la RSSN. En el momento de la visita, los albergues visitados estaban siendo evaluados para ser tenidos en cuenta e incluirlos de manera oficial.

\subsubsection{Los albergues como lugares de (des)protección}

La implementación de la RSSN implica la incorporación por parte de los albergues socios de categorías de protección diferenciadas, como es el caso de las personas LGTBI o de las solicitantes de asilo. Esto ha supuesto en muchas ocasiones un reto y una modificación en las formas de intervención directa de los albergues, especialmente, en aquéllos gestionados por alguna congregación eclesiástica, por ejemplo, implementar "módulos LGTBI", es decir, habilitar habitaciones reservadas independientes en el interior de los albergues. El objetivo de estos módulos es dotar a los albergues de espacios de protección específicos para personas LGTBI a través de un espacio físico diferenciado; además de capacitar al personal para realizar posibles derivaciones y apoyo especializado. En teoría, estos espacios están concebidos para evitar discriminación, tratos degradantes, problemas de abusos o acoso, maltrato o violencias ejercidas en el interior de los albergues.

Con respecto a la implementación de los módulos LGTBI, como bien se ha mencionado no están definidos los criterios en ningún documento oficial del ACNUR por lo que no existen pautas claras ni concretas sobre cómo deberían ser físicamente o cómo hacerlos funcionales, por lo tanto, existe una gran variedad de "módulos LGTBI" en la red de albergues. En su mayoría, se presentan como una habitación separada para las personas autodefinidas como LGTBI que quieran utilizarla. Sin embargo, se observa una gran disparidad en la conformación de estos módulos, por ejemplo, algunos incluyen 
baños como parte del módulo; otros módulos cuentan con puertas que cierran desde afuera con llave; otros son habitaciones abiertas con literas o son espacios amplios con camas y conectados con el resto del albergue.

Así mismo, se observa diversidad para identificar o señalar los módulos. En primer lugar, existen albergues que identifican el módulo con una bandera multicolor en un lugar visible $\left(\mathrm{NC}^{13}\right)$. En segundo lugar, aquellos sin señalamiento alguno por diversas razones, entre ellas, motivos religiosos, descuerdo con la categoría de protección "LGTBI" sugerida por el ACNUR (NC3), para evitar la estigmatización (NC7) o debido a que la habitación se destina a la protección de varios grupos vulnerables y no tendría sentido identificarla solo con una categoría (NT7).

Durante el trabajo de campo se evidenció la existencia de posturas reacias a la protección especial de la diversidad sexual (NC3), sobre todo, en los espacios ligados a la religión de corte conservador. En definitiva, coexiste una variedad de formas en la que los albergues presentan, implementan y gestionan estos módulos. Se trata de una realidad compleja y diversa, por lo tanto, las respuestas desde las administraciones de los albergues también lo son.

\subsubsection{Albergues abiertamente reacios a desarrollar mecanismos de protección LGTBI}

Los albergues que se muestran abiertamente reacios a desarrollar mecanismos específicos de protección para las personas LGTBI son escasos, uno de ellos, es el caso de Tecún Umán donde se observó un rechazo específico, manifiesto y verbalizado a implementar y/o desarrollar mecanismos de protección. Durante la visita a este albergue, la persona responsable se mostró abiertamente molesta por ser obligada a hablar sobre la diversidad sexual e incluir el trato diferenciado; asimismo, refirió sentir miedo de aceptar personas LGTBI:

...miedo de recibirlos tenemos, porque quieren ser especiales... exigen cosas, hay mucha gente LGTBI que no busca refugio ni asilo, se van porque se ha hecho propaganda porque son.... porque los hacen menos. Quieren pasarse por mujeres. Hay homosexuales que van y provocan un escándalo, si se quedan dos o tres días empiezan a alborotar todo (NC3).

13 NC: notas de campo 
Esta misma persona se mostró adversa a alojar mujeres transgénero sobre el argumento de que "se cambian de ropa, se visten de minifalda y van en busca de fiesta" (NC3). Asimismo, interpreta las medidas de especial protección como un privilegio hacia las personas LGTBI y, por consecuencia, una discriminación hacia el resto de la población. Dado su desacuerdo con las exigencias del ACNUR, y pese a estar situado en un punto clave entre México y Guatemala, en el momento de la investigación, se había negado a implementar medidas de protección específicas para personas LGTBI.

Asimismo, algunas personas encargadas consideran al financiamiento del ACNUR como un aliciente para incluir los módulos LGT$\mathrm{BI}$ en sus albergues.

\subsubsection{Albergues que aceptan con ciertas reservas a desarrollar mecanismos de protección LGTBI}

La Casa del Migrante de Ciudad de Guatemala sigue rigurosamente las indicaciones del ACNUR, cuenta con un personal altamente capacitado y especializado para realizar las derivaciones a entidades y asociaciones con experiencia en el área de protección LGTBI. Dispone de un módulo LGTBI indicado, separado del resto de habitaciones y una buena coordinación con el resto de agentes participantes de la RSSN.

En tanto que la Casa del Migrante en Petén (Guatemala) y la Casa Mambré en la Ciudad de México aceptan, pero con reservas. Por ejemplo, la Casa del Migrante en Petén, durante la entrevista sobre la atención a la diversidad sexual, la persona responsable del albergue señaló: "no voy a tratar a una pareja gay como si viniera el rey Felipe II, en el albergue todo el mundo es igual" (NC2), añadiendo que "estos maricones existen, pero eso no significa que van a ser tratados mejor" (NC2). En ocasiones, la presencia de personas LGTBI se interpreta como una carga difícil de manejar: se "agradece" que "los saquen del albergue" ya que van "pintados, con pelucas, les molesta y los insultan" y llegan tarde (NC2).

2.3.4. Albergues que responden de manera flexible o adaptada a las propuestas de protección LGTBI

Otros albergues responden de manera flexible-adaptada en la defensa de derechos LGTBI. En este sentido son espacios con ins- 
talaciones adaptadas y con recursos para proteger de mejor manera a este colectivo. El personal entiende que la protección no viene necesariamente de un espacio físico y centran sus repuestas en generar un espacio abstracto de seguridad, por ejemplo, FM4 (México) tiene un módulo reservado a casos de alta vulnerabilidad y uno específicamente para personas LGTBI con baños incluidos. Sus módulos son flexibles para diferentes grupos vulnerables, entre ellos, personas LGTBI. Es decir, dependiendo de los perfiles de las personas albergadas se habilitan módulos específicos. Por cuestiones logísticas, pero sobre todo para evitar el estigma, los módulos no son identificados con ningún símbolo. El foco está puesto en la capacitación permanente del personal del albergue con el objetivo de crear un ambiente de respeto constante, esa parece ser la clave para generar espacios seguros de protección. El testimonio de un hombre homosexual refleja la percepción de protección y seguridad.

FM4 siempre trata de buscar lo que uno necesita...Bien. Todo el día repiten las reglas...el respeto, yo ahi si me sentía a gusto...por primera vez en mi vida (E9).

Este trabajo constante se combina, según el mismo testimonio, con otras medidas de seguridad como cámara de seguridad:

...en FM4 hay cámaras y ahí a fuera del albergue no te pueden hacer nada (E9).

Las entrevistas reflejan que, independientemente de la existencia de un módulo específico, la protección de las personas LGTBI depende de la convicción y ambiente de protección y no de una estructura física concreta. Es decir, existen albergues donde, aun implementado un módulo LGTBI, se observan vulneraciones graves de derechos, mientras otros que, sin tener un espacio físico determinado, consiguen generar un espacio de protección para el colectivo LGTBI a través de un personal consciente y capacitado como es el caso de FM4 en Guadalajara, México.

Algunos de testimonios recogidos reflejan cómo el hecho de contar con módulos específicos no implica necesariamente protección ni seguridad. Una mujer transgénero alojada en casa Mambré relataba: 
... hay mucha deficiencia porque Mambré al principio es lo más hermoso que puede haber porque...te dan comida, te dan ropa... te dan vivienda, no tienes problema de ninguna indole... pero si usted entra a Mambré y le dice... ¿me muestra los espacios de mujeres? ¿Me muestra los espacios de hombres y me puede mostrar los espacios de las chicas trans? ... ahi va a ver la diferencia entre todas las demás, porque el de las mujeres tiene su espacio... tienen su buró a la par, o sea tienen bonito sus cuartos, los hombres también están bien acomodados...pero no... las trans están metidas en una bodega donde hay tres camarotes y hay un espacio chiquitico (E3).

Otras personas entrevistadas encontraban en la propia estructura de los módulos una discriminación.

...la habitación está bien, pero es muy reducido...es muy angosto la verdad (E4).

\subsubsection{Albergues como facilitadores de situaciones de (des)protección}

El contexto generalizado de discriminación y la identidad como persona LGTBI en los albergues acarrea un estigma que favorece la exposición a la violencia, tratos discriminatorios y degradantes. Ante ello, como una medida de protección, las personas pertenecientes a ese colectivo evitan los espacios de la RSSN y, en concreto, los módulos LGTBI. En los siguientes párrafos se expondrá una serie de situaciones en los albergues vividas por las personas LGTBI a lo largo de su proceso migratorio.

\section{a) Evitar albergues como estrategia de protección personal}

Como estrategia de protección, las personas LGTBI deciden, por un lado, no identificarse como tales y, por otro, evitan el uso de los albergues o los módulos destinados para su protección, pues los identifican como áreas de alta desprotección y donde se exponen a un peligro mayor ${ }^{14}$. Sin embargo, para ello es necesario contar con

14 Los albergues concentran grupos heterogéneos de personas entre las cuales se encuentran los propios perpetradores. En el caso de Centroamérica y México es común la presencia de miembros de pandillas en el interior o en los alrededores de los albergues. 
una red de apoyo o, en su defecto, con medios económicos suficientes para pagar hoteles o pensiones alternativas.

Esta tendencia se observa en el testimonio de un hombre homosexual en Tapachula, quien tras sospechar que a las afueras del albergue $^{15}$ podría haber miembros de pandillas de quienes venía huyendo, él y su pareja decidieron buscar otro sitio para pernoctar.

...yo creo que eran como las 9 de la noche...pero inclusive había muchos ahi afuera...nosotros decidimos no quedarnos ahi porque vimos a unos tipos discutiendo, a otros fumando marihuana en el mismo costado del albergue y empezaron a hablar también de cosas de pandillas y nosotros venimos huyendo de cosas de pandillas...y quedarnos en el medio de pandilleros (E1).

Esta persona salió de El Salvador y en su paso por Guatemala no utilizó ningún albergue, al cruzar la frontera de México y rencontrarse con su pareja, buscaron una pensión o albergue que no perteneciera a la RSSN.

Las entrevistas reflejan que las personas LGTBI, sobre todo, las mujeres transgénero en contacto con asociaciones y/o políticamente activas, se apoyan en una incipiente red de auto-ayuda que las ha apoyado para cruzar Guatemala y llegar hasta Ciudad de México sin recurrir a la RSSN. Las redes de apoyo mutuo son una fuente de información sobre cómo evitar situaciones de peligro o de desprotección, ofreciendo algunos contactos o personas de apoyo en el camino (Morondo y Lo Coco, 2018, p. 21).

Cuando las personas LGTBI no cuentan con redes de apoyo ni con medios económicos necesarios, los espacios seguros de la RSSN son la única opción, no sin enfrentar dificultades para acceder a éstos. Los testimonios reflejan situaciones en las cuales se ha negado el acceso a mujeres transgénero, un hecho significativo y preocupante.

...se me quedó mirando de pies a cabeza y me dijo "no, tú no puedes entrar"16 (E6).

15 En el momento de la investigación este albergue era el principal socio del ACNUR en Tapachula, Chiapas (México).

16 La persona entrevistada no recuerda con precisión el albergue en el que se le negó la entrada. 


\section{b) Pertenecer al colectivo LGTBI genera discriminación, malos tratos y mayor vulneración}

La visibilidad de las personas LGTBI puede aumentar los niveles de violencia ejercidos en su contra. Los albergues no son espacios desconectados del mundo, operan las mismas lógicas de discriminación y violencia del conjunto de la sociedad. El testimonio de un hombre homosexual, solicitante de asilo en Tapachula, es un ejemplo de la violencia enfrentada durante su proceso migratorio. Esta persona se encontraba en Tapachula en espera de la resolución de su solicitud de asilo ante la COMAR ${ }^{17}$, razón por la cual no podía salir del Estado de Chiapas (México). Cabe señalar que durante el periodo de espera una persona no tiene posibilidad de obtener apoyo de alojamiento más allá de la permanencia por unos días en el albergue Belén o a un recurso de emergencia por un tiempo determinado del ACNUR, por lo que esta persona se vio obligada a trabajar sin la documentación oficialmente requerida, para poder alquilar una habitación. Según señaló, durante el trayecto a su trabajo sufrió una violación sexual:

Hay algo que pasó... si lo denuncio no sirve de nada...porque... son mismos policías...sí...en realidad lo de mi sangrado, como yo quedé, que no me podían hacer ni los tactos de como yo tengo perforado...cerca de la colonia, yo fui obligado a tener relaciones sexuales, y son policías...uniformados...que ya nos conocen y sabian que con mi pareja ...salíamos agarrados de la mano y que nos veían abrazados... "somos policías y tú eres un migrante.... además ya sabemos dónde vives...y y sabemos" ....y entonces de que me sirve, por eso no quiero estar aqui en Tapachula (E1).

A pesar de que esta agresión no sucedió, según el testimonio, en el interior de un albergue, resulta significativo por varias razones. La primera refleja las consecuencias por mostrarse abiertamente homosexual o LGTBI en una sociedad con altos grados de violencia contra los grupos vulnerables, más preocupante aun si dicha agresión provino de un cuerpo de seguridad pública. La segunda evidencia cómo el hecho de no contar de facto con espacios seguros, expo-

17 Comisión Mexicana de Ayuda al Refugiado responsable de conducir la política en materia de refugiados y protección complementaria en México. Véase: https://www.gob.mx/comar 
ne a estas personas a situaciones de mayor peligro. En el momento de la entrevista esta persona no estaba en condiciones de salud para trabajar, por lo que su grado de vulnerabilidad era aún mayor.

El abandono repentino por parte de las personas LGTBI de los albergues aparece también como consecuencia de la discriminación sufrida en el interior de éstos. Tal fue el caso de dos mujeres transgénero.

...de allí, me salí también porque... yo no estoy a favor de las injusticias y de las preferencias... (E5)

...yo solo duré un mes [en Mambré] porque yo no soporté eso (discriminaciones) (E3).

Los tratos degradantes provocan situaciones de vulneración de derechos y, en ocasiones, conlleva a una situación aún más crítica. Tal fue el caso de un hombre homosexual obligado a huir de un albergue por los malos tratos sufridos, al salir fue víctima de abuso sexual en los alrededores del albergue.

...como que me dio mucho asco... me quiso abusar y me dio mucho asco...fue en la puerta de a fuera', 'en ese albergue no hay ese tipo de seguridad' 'ay pero si eres gay yo sé que te va a gustar...y me empezó a tocar' 'me da asco y pena (E9).

Otra forma de discriminación es el estigma hacia persona LGTBI y el VIH. En una entrevista en la Ciudad de México, una mujer transgénero mencionó haber sido obligada a realizarse pruebas de VIH para poder permanecer en el albergue.

Oye, mañana las llevas a hacer las pruebas del VIH porque si ellas no tienen la prueba del VIH no pueden estar aquí...si no te gustan mis reglas... ahí está la puerta (E3).

Como consecuencia de este trato, la mujer decidió abandonar el albergue al día siguiente, provocando una salida forzada.

Durante el trabajo de campo en Tapachula (México), se realizó una actividad grupal (GD1) en la cual las personas participantes, quienes habían recurrido a los espacios seguros, mencionaron ser víctimas de estigmatización, al llegar a los albergues la gente las señala gritando: "carne fresca". En el momento de ser identificas como personas LGTBI, en los albergues comienza una exposición a tratos discriminatorios y agresivos. En este mismo sentido, algunos res- 
ponsables de albergues expresaron la situación de exaltación ante la presencia de las mujeres transgénero. El responsable de la Casa del Migrante en Petén señaló:

...el año pasado vinieron solamente tres trans(género) que salieron a trabajar a la noche y que todo el mundo les chiflaba cuando salieron a trabajar porque evidentemente los migrantes no van con bolso y tacones...peinadas y maquilladas... Después se fueron (NC2).

El análisis de los datos muestra la escasa seguridad, la desprotección en los espacios seguros y la violencia ejercida contra las personas pertenecientes al colectivo LGTBI. A lo cual se agrega actitudes normalizadas del personal de los albergues de la RSSN; así como por las mismas personas LGTBI. Tal y como se muestra en el siguiente testimonio, una mujer transgénero en un albergue evangelista en la Ciudad de México.

...el pastor...esa noche fue horrible...nos exigió la prueba de VIH a fuerzas... bueno pues por mí no hay ningún problema... yo se la puedo dar...no tengo porque negarme a algo pues...me lo piden... como le digo yo nunca he estado en información... de gays... ni trans ni nada del estilo... Por eso yo no sé si me están agrediendo (E5).

El hecho de la existencia de áreas físicas denominadas "espacios seguros" o "módulos LGTBI" no significa seguridad ni protección para las personas LGTBI. Los módulos pueden servir o convertirse en cárceles y lugares de encierro, tal y como se verá en el siguiente apartado.

\section{c) Módulos LGTBI como espacios de reclusión}

Una práctica habitual en algunos albergues es encerrar bajo llave a las mujeres transexuales durante la noche en el módulo LGTBI. Las obligan a entrar y salir en determinados horarios. Durante el trabajo de campo se constató dicha práctica mediante una actividad grupal (GD1) en uno de los albergues, además de visitar el módulo donde esto sucedía: una habitación con rejas en las ventanas. Todas las personas que participaron en GD1 confirmaron el encierro durante las noches, los horarios diferenciados y la inseguridad ex- 
puesta al estar encerradas en el caso de presentarse un accidente o cualquier situación de emergencia.

Yo no pensé que iba estar encerrada como presa y eso en las noches... fuimos muchas las que nos quejamos porque a los varones los dejaban libres y a nosotras nos encerraban con llave... nos dejaban una ventanilla abierta y no ponían ni cortinas ni nada de eso (E4).

El análisis del GD1 muestra cómo los módulos LGTBI, en ocasiones, son utilizados como espacios de reclusión, confirmando que un espacio físico diferenciado no está directamente relacionado con la seguridad.

Dicen que por seguridad... por veces si (nos sentíamos más seguras) y por veces no...por algún accidente...un incendio...o le pegaban un palo a alguien... y lo otro por los hombres...sí ...porque hay hombres malos ahí. También llegan pandilleros (GD1).

Cuando íbamos a dormir nos molestaban también...salían de los cuartos...nosotras paradas así...esperando que nos metieran en el cuarto...nos volteábamos así, porque estaban todos desnudos, nos meten llave, estuvimos encerradas con llave. No podíamos entrar en el cuarto' 'ellos dicen que por seguridad... a las 5 y media te levantan...antes era a las 5 pero como dicen que nosotras nos tardamos para maquillarnos (GD1).

d) Discriminación en la gestión diaria de los albergues

La discriminación imperante y arraigada en el personal de algunos albergues hacia las personas LGTBI genera una distribución en inequidad de las tareas diarias y, al mismo tiempo, causa una inquietud y pesadumbre sobre éstas de negarse a ejecutar las tareas asignadas, pues podrían ser expulsada del espacio y dejarlas totalmente desprotegidas y expuestas a más violencia.

Los testimonios describen cómo los turnos de limpieza son asignados a las mujeres transgénero, situaciones que no son denunciados por las víctimas por temor a sufrir represalias.

Ellos quieren que uno haga las cosas dos, tres veces...o toda la semana si es posible... nosotras las trans... a esta niña [señala la cama] la ponen todos los días a lavar los baños...los baños de las mujeres todos los días, luego la llaman para limpiar abajo... (E4). 
Esta misma persona señala el reparto a su entender desigual en las tareas del albergue.

...excelente en la atención y todo eso...solo que a veces en el aseo me toca a mi y me regañan...la verdad...la limpieza de los sanitarios es de todos...siempre a las chicas trans nos dejan el aseo de eso. Las mujeres... en Mambré son muy discriminatorias...o sea...no están sensibilizadas o personal para trabajar con LGTBI... a nosotras ${ }^{18}$ siempre nos toca los más pesado (E3).

Otro ejemplo de discriminación es el reparto de los enseres necesarios para la vida diaria, en este caso de colchas: "no, para ti no hay" (E3). Esta acción discriminatoria obligó a la persona a abandonar el albergue, tras lo cual, encontró un piso sin mobiliario suficiente, debiendo dormir en el suelo.

A lo anterior se agrega, la discriminación en otro tipo de conductas menos permisivas, pero no dejan de ser ofensivas y discriminatorias.

quita(ba)n su teléfono todas las noches...pero a los que ellas quieren... a algunas personas...uno no habla por miedo porque lo vayan a echar a media noche...por ejemplo hace una semana sacaron a una amiga mía (trans) a media noche...ellos se quieren deshacer de uno, me entiendes?' 'Esa señora hasta la policía le tiró como a las 11 de la noche la sacaron de aquí (E6).

La discriminación no solo se expresa en la asignación de tareas sino con un trato despectivo hacia las personas LGTBI. Una mujer transgénero relató:

...lo discrimina mucho a uno, incluso una persona que es voluntaria de aquí... o trabajadora no sé qué será, me dijo que la próxima vez me los iba a tirar en la cara, los frijoles...no me trates así yo no te estoy faltado al respeto...mucho lo discriminan a uno, yo les pido algo...no sé, un cepillo, un jabón y te lo dan de mala gana, o si no te gritan...ellas ${ }^{19}$ son muy discriminativas con nosotras (E6).

Todas las personas LGTBI ubicadas en el módulo en la casa Mambré mencionaron haber estado sin luz por más de una semana en la

\footnotetext{
Se refiere a centroamericanas y mujeres transgénero.

19 Se refiere a algunas de las voluntarias y trabajadoras, no a todo el personal.
} 
habitación, pese a haber avisado a los responsables. Otra persona (un hombre homosexual proveniente de Honduras) señaló cómo, a pesar de tener que caminar con prótesis a causa de la amputación de sus dos piernas y de haber perdido casi la totalidad de los dedos de las manos se le requería en la limpieza de los baños.

...te digo que traigo ahorita una herida muy complicada... así como una llagas ${ }^{20} \ldots y$ si, estuve viendo al doctor...pues la otra vez...con una de las encargadas...no tuve un encontronazo pero pues no me quisieron apoyar, yo les dije que si me permitían quedarme el celular para poder ver porque como no había luz para limpiarme y me ignoraron...luego les dije que si me apoyaban porque necesitaba levantarme temprano porque me tocaba limpiar los baños entonces tenía que levantarme temprano porque...tenía una cita aquí en Médicos sin Fronteras y pues sí son muchas cosas...que no están bien...muchas personas no dicen nada por temor a que los corran ${ }^{21}$ (E7).

No solo los testimonios sino la observación en el propio albergue, revelan las grandes dificultades a las cuales se enfrentan las personas con diversidad funcional, aunado al estigma LGTBI, termina siendo un factor generador de una gran desprotección.

e) Trabajo sexual, estigma y gestión de albergues: algunos apuntes

La discriminación enfrentada por las personas LGTBI ocasiona la reclusión en nichos de trabajo precarizado y marginal. Esta situación es, especialmente, grave en las mujeres transexuales quienes suelen dedicarse al trabajo sexual como única fuente de ingresos durante su proceso migratorio. Por cuestiones de seguridad, los albergues tienen horarios muy estrictos de entrada y de cierre sobre todo durante las noches. El trabajo sexual suele funcionar en los horarios nocturnos, generalmente incompatibles con las normas de los albergues. En este sentido, algunos testimonios reflejan las dificultades de gestión con los responsables de las casas. Por ejemplo, en el albergue Belén en Tapachula:

...ella y yo salimos a buscar trabajo...nos quedamos dos noches afuera porque perdimos el boletito...el papelito...porque llegamos demasiado tarde (GD1).

20 Las heridas causadas por las prótesis en los muñones de sus piernas.

21 Las expulsan del albergue a consecuencia de la queja. 
El testimonio narra la vivencia de dos mujeres transgénero tras haber sido explotadas laboralmente en una "pollería"22 donde se negaron a pagar los días trabajados, debido a ello, se vieron obligadas a realizar trabajo sexual. El guardia del albergue Belén, les advirtió "vénganse temprano para renovar el cupo". Las mujeres aclaran que los guardias fueron amables, buenas personas, pero aun así al no poder cumplir el horario se quedaron afuera del albergue dos noches.

Existe un estigma asociado a las mujeres transgénero con respecto al trabajo sexual y ello genera un temor en algunos albergues, razón por la cual se incrementa el nivel de control sobre esta población.

...todos nos vigilan y eso son reglas que uno tiene que respetar por parte de la casa, para mi está bien. Sí, siento que me están controlando y eso no tiene que ser así, nos llaman la atención...que tenemos que estar más distantes de los hombres y todo eso (E4).

...en todo tú no te puedes acercar ahí, no puedes hacer esto, no tienes que ir a los baños tal...tu esto...tu esto... ustedes dos van a tener que dormir ahi aparte, si quieres utilizar los baños de hombres tienen que avisarme, si quieren hablar con hombres o con mujeres no les está permitido" (E4).

La RSSN es un proyecto en gestación que requiere de tiempo para su consolidación y para saber si va logrando su cometido; sin embargo, es necesario tener en cuenta la voz de las personas a quienes va dirigido y, de esa manera, saber de fuentes directas la existencia de lagunas o factores que puedan obstaculizar el logro de sus objetivos.

\section{CONCLUSIONES}

La comunidad internacional ha desarrollado mecanismos de protección destinados a las personas LGTBI sobre los cuales el ACNUR ha puesto en marcha la Red Regional de Espacios Seguros en el NCA y México; sin embargo, es evidente la necesidad de un trabajo más profundo de concientización y en coordinación con todos los actores locales e internacionales que trabajan en la región sobre la gestión de la migración y la protección de derechos humanos.

22 Establecimiento de venta de pollos. 
El análisis de los datos refleja violación de derechos humanos:

- Discriminación por cuestión de identidad de género y orientación sexual en espacios seguros.

- Violencia estructural sobre grupos vulnerables en los espacios seguros.

- Actitudes xenófobas, tránsfobas y homáfobas en la cotidianeidad de la gestión de los espacios seguros.

Esta situación induce a las personas por la cuales se justifica la existencia de la RSSN a buscar espacios alternativos, igualmente, en una sociedad donde la violencia está normalizada, que les discrimina y rechaza por su identidad sexual y situación migratoria. Todo lo anterior se traduce en desprotección, agravando aún más su situación al carecer de redes de apoyo local.

El marco de la investigación muestra la necesidad de poner el foco en el elemento abstracto de los espacios de protección a la par que, en el espacio físico, ambos deben complementarse para así construir espacios seguros. Es decir, las experiencias recogidas evidencian la necesidad de trabajar tanto con la sociedad en general como con las personas de primer contacto con los grupos vulnerables sobre temas de derechos humanos, violencia y perspectiva de género, diversidad sexual y cultural e inclusión social; lo mismo que con las autoridades locales y nacionales, pues ellas son responsables de velar por los derechos humanos de las personas que se encuentran en su territorio, independientemente de su identidad sexual y situación migratoria. Los espacios seguros se han de construir a través de la combinación entre lo abstracto y lo físico, solo de esta manera se llegará a disminuir los elevados grados de discriminación y violencia que sufre esta población a lo largo del camino.

\section{BIBLIOGRAFÍA}

ACNUR (2010). Mesa redonda de expertos organizada por el Alto Comisionado de las Naciones Unidas para los Refugiados Conclusiones finales: Solicitantes de asilo y refugiados que buscan protección debido a su orientación sexual e identidad de género. Ginebra, Suiza 30 de septiembre -1 de octubre 2010 [versión digital]. Recuperado de https://www. refworld.org.es/docid/4d11bb2a2.html 
- (2012). Compilación de buenas prácticas en materia de edad, género y diversidad Oficina para las américas [versión digital] Recuperado de https:// www.refworld.org/docid/50519dba2.html

- (2012). Directrices sobre protección internacional no. 9: Solicitudes de la condición de refugiado relacionadas con la orientación sexual y/o la identidad de género en el contexto del artículo 1A (2) de la Convención sobre el Estatuto de los Refugiados de 1951 y/o su Protocolo de 1967. HCR/IP/12/09.

- (2015). Estrategia de Protección y Soluciones para el Triángulo del Norte de América Central 2016-2018 [versión digital] Recuperado de http://reporting.unhcr.org/sites/default/files/Protection $\% 20$ and $\% 20$ Solutions $\% 20$ Strategy $\% 20$ for $\% 20$ the $\% 20$ Northern $\% 20$ Triangle $\% 20$ of $\% 20$ Central $\% 20$ America\%202016-2018.pdf

- (2015). Protección de las personas con orientación sexual e identidad de género diversas [versión digital] Recuperado de https://www.acnur. org/5b6c527b4.pdf

- (2014). La protección internacional de las personas LGBTI [versión digital] Recuperado de https://www.acnur.org/fileadmin/Documentos/Publicaciones/2014/9872.pdf.

- (2016). La protección de los refugiados y la migración mixta. El plan de los 10 puntos en acción. Ginebra [versión digital] Recuperado de https:/www.refworld.org/cgi-in/texis/vtx/rwmain/opendocpdf. pdf?reldoc $=$ y\&docid $=4$ df9ffb 92

- (2018). Tendencias globales de desplazamiento forzado en 2018 [versión digital] Recuperado de https://www.acnur.org/5d09c37c4.pdf

- (2018). Spaces Network and Human Right Center, El silencio que cargo. Revelando la violencia de género en desplazamiento forzado. Guatemala y México. Informe exploratorio.

- (2019a). Hoja informativa. Situación en el Norte de Centroamérica [versión digital] Recuperado de https://www.acnur.org/5d52d27e4.pdf

- (2019b). Red Regional de Espacios Seguros de las Américas Lecciones Aprendidas y Herramientas [versión digital] Recuperado de https://www. acnur.org/5c87fe7e4.pdf

Bobbio, N. (1990). El tiempo de los derechos. Madrid: Editorial Sistema.

Comisión Interamericana de Derechos Humanos (2015). Violencia contra Personas Lesbianas, Gay, Bisexuales, Trans e Intersex en América. OEA/ Ser.L/V/II. Rev.2.Doc. 36 [versión digital] Recuperado de www.cidh.org

- (2017). comunicado de prensa 37/17 [versión digital] Recuperado de http:// www.oas.org/es/cidh/prensa/comunicados/2017/037.asp

- (2018). Reconocimiento de derechos de personas LGBTI [versión digital] Recuperado de http:/www.oas.org/es/cidh/informes/pdfs/LGBTI-ReconocimientoDerechos2019.pdf

Comisionado Nacional de los Derechos Humanos Honduras (2018). Informe anual [versión digital] Recuperado de http://app.conadeh.hn/descargas/ Informe\%20Anual\%20CONADEH\%202018.pdf 
Declaración de Cartagena sobre Refugiados, Coloquio sobre la Protección Internacional de los Refugiados en América Central, México y Panamá, 22 de noviembre de 1984, [versión digital] Recuperado de http://www. refworld.org

Eguren, E. (2014). The Notion of Space in International Accompaniment, Peace Review, no. 27 (1), 18-24.

Ferri, E. G. (2012). The politics of protection: The limits of humanitarian action. Brookings Institutions press: Washington, D.C.

Mahoney, L., y Eguren, E. (2004). Territorilly-based alternatives in the Colombian Conflict, Collaborative Learning Projects, MA USA: Cambridge.

Morondo Taramundi, D., y Lo Coco, D. (2018). Estudio sobre la situación de las personas LGTBI del norte de Centroamérica con necesidades de protección internacional en Guatemala y México, Agencia Española de Cooperación Internacional [versión digital] Recuperado de https://www.aecid. es/Centro-Documentacion/Documentos/Acci\%C3\%B3n\%20Humanitaria/Estudio\%20LGBTI\%20Norte\%20Centroamerica.pdf

Seelinger, K. T., y Freccero, J. (2013). Safe Haven. Shetering displaced persons from sexual and gender-based violence. Comparative report, Human Rights Center, University of California. [Versión digital] Recuperado de www.refworld.org

Principios de Yogyakarta sobre la Aplicación de la Legislación Internacional de Derechos Humanos con relación a la Orientación Sexual y la Identidad de Género [versión digital] Recuperado de http://yogyakartaprinciples.org/principles-sp/about/ 


\section{ANEXO I}

TABLA DE CODIFICACIÓN DE ENTREVISTAS CITADAS

\begin{tabular}{|l|l|l|l|l|}
\hline CóD. & Nacionalidad & \multicolumn{1}{|c|}{ Categoría ACNUR } & \multicolumn{1}{|c|}{ Entrevista } & $\begin{array}{l}\text { Orientación/ldentidad } \\
\text { de Género }\end{array}$ \\
\hline E123 & Salvadoreña & Solicitante de asilo & Tapachula & Hombre homosexual \\
\hline E2 & Salvadoreña & Refugiados & Tapachula & $\begin{array}{l}2 \text { hombres } \\
\text { homosexuales }\end{array}$ \\
\hline E3 & Salvadoreña & Solicitante de asilo & CDMX & Mujer transgénero \\
\hline E4 & Hondureña & Protección complementaria & CDMX & Mujer transgénero \\
\hline E5 & Salvadoreña & Visa humanitaria & CDMX & Mujer transgénero \\
\hline E6 & Hondureña & Solicitante de asilo & CDMX & Mujer transgénero \\
\hline E7 & Hondureña & Visa humanitaria & CDMX & Hombre homosexual \\
\hline E8 & Guatemalteca & Refugiada & CDMX & Mujer transgénero \\
\hline E9 & Hondureña & Refugiado & Guadalajara & Hombre homosexual \\
\hline E10 & Hondureña & Refugiada & Saltillo & Mujer transgénero \\
\hline E11 & Salvadoreña & Refugiados & Saltillo & $\begin{array}{l}\text { 2 hombres } \\
\text { homosexuales (las } \\
\text { mismas personas } \\
\text { que E2) }\end{array}$ \\
\hline E12 & Salvadoreña & Refugiada & Tapachula & Mujer transgénero \\
\hline E13 & Guatemalteca & Desplazada interna & Quetzaltenango & Mujer lesbiana \\
\hline E14 & Guatemalteca & Desplazada interna & Quetzaltenango & Mujer transgénero \\
\hline GD241 & $\begin{array}{l}\text { Salvadoreña (1) y } \\
\text { hondureña (4) }\end{array}$ & Solicitantes de asilo & mujeres transgénero \\
\hline
\end{tabular}

23 Entrevistas

24. Grupo de discusión 